\title{
Decrease in chemosensitivity against anticancer drugs by an esophageal squamous cell carcinoma SEREX antigen, AISEC
}

\author{
TAKAKI HIWASA ${ }^{1}$, HIDEAKI SHIMADA ${ }^{3}$, MARI KUBOSHIMA ${ }^{1,2}$, TOORU SHIRATORI ${ }^{2}$, \\ AKIKO KAGAYA ${ }^{1,2}$, YOSHIHIRO NABEYA ${ }^{2}$, SUMIO SUGANO ${ }^{4}$, TAKENORI OCHIAI ${ }^{5}$, \\ HISAHIRO MATSUBARA ${ }^{2}$ and MASAKI TAKIGUCHI ${ }^{1}$
}

\author{
${ }^{1}$ Departments of Biochemistry and Genetics and ${ }^{2}$ Frontier Surgery, Chiba University, Graduate School of Medicine, 1-8-1 \\ Inohana, Chuo-ku, Chiba 260-8670; ${ }^{3}$ Division of Gastroenterological Surgery, Chiba Cancer Center, 666-2 Nitona-cho, \\ Chuo-ku, Chiba 260-8717; ${ }^{4}$ Department of Medical Genome Science, Graduate School of Frontier Sciences, \\ The University of Tokyo, 5-1-5, Kashiwanoha, Kashiwa, Chiba 277-8562; ${ }^{5}$ Gastroenterological Center, \\ San-Ai Memorial Hospital, 2-11-15 Miyazaki, Chuo-ku, Chiba 260-0806, Japan
}

Received June 25, 2008; Accepted September 12, 2008

DOI: 10.3892/ijo_00000189

\begin{abstract}
We performed SEREX (serological identification of antigens by recombinant cDNA expression cloning) using the sera of patients with esophageal squamous cell carcinoma (SCC), and examined whether some of the SEREX antigens can affect chemosensitivity against anticancer drugs. We isolated a novel gene which was designated as AISEC (antigen identified by SEREX for esophageal carcinoma). RT-PCR analysis showed that the mRNA expression levels of AISEC were higher in esophageal SCC tissues than in their normal counterparts. By transfection into activated Ha-ras-transformed NIH3T3 (ras-NIH) mouse fibroblasts, we isolated a clone, FAISEC-3, which stably expressed AISEC. FAISEC-3 cells were more resistant to anticancer drugs, such as mitomycin $\mathrm{C}$, ifosfamide, vincristine, camptothecin and etoposide,
\end{abstract}

Correspondence to: Dr Takaki Hiwasa, Department of Biochemistry and Genetics, Chiba University, Graduate School of Medicine, 1-8-1 Inohana, Chuo-ku, Chiba 260-8670, Japan

E-mail: hiwasa_takaki@faculty.chiba-u.jp

Abbreviations: ACNU, methyl-nitro-ureido-deoxy-glucopyranoside; 5-AIQ, 5-aminoisoquinolinone; AraC, cytosine arabinoside; CDDP, cis-diammine dichloroplatinum (II); CPT, camptothecin; 5-FU, 5-fluorouracil; IFM, ifosfamide; IPTG, isopropyl B-D-thiogalactoside; MMC, mitomycin C; MTT, 3-(4,5-dimethylthiozol-2yl)-2,5-diphenyltetrazolium bromide; MTX, methotrexate; PARP, poly(ADP-ribose) polymerase-1; RT-PCR, reverse transcriptasePCR; SCC, squamous cell carcinoma; SEREX, serological identification of antigens by recombinant cDNA expression cloning; VCR, vincristine; VP-16, etoposide

Key words: esophageal squamous cell carcinoma, SEREX, MTT assay, p53, Luciferase assay than parental ras-NIH cells. Luciferase reporter assay after a transient transfection with AISEC cDNA or the control vector revealed that the transactivity of p53 was suppressed by AISEC in a dose-dependent manner. These results suggested that esophageal SCC tissues produce AISEC in increased amounts, which can reduce the chemosensitivity against anticancer drugs possibly by suppressing the p53 transactivation ability.

\section{Introduction}

Human esophageal squamous cell carcinoma (SCC) is a highly malignant disease (1). Therefore, an early diagnosis using tumor markers is indispensable for preventing tumor development. We previously performed large scale SEREX screening, and reported new tumor antigens of esophageal SCC (2-8). Among them, TROP2/TACSTD2, SLC2A1 and TRIM21 have gained a lot of attention because their serum antibodies have frequently been developed in patients with esophageal SCC $(2,4,5)$. In addition most, if not all, of the esophageal SEREX antigens have been suggested to be related to carcinogenesis, apoptosis or cell growth (6). For example, tumor suppressor p53, oncoprotein phosphatidylinositol 3-kinase and stathmin were isolated by our SEREX screening method.

p53 is activated after administering DNA-damaging anticancer drugs, which may, at least in part, account for the tumor-specific cytotoxic activity of anticancer drugs. One of the typical targets of p53 transactivation is $\mathrm{p} 21^{\mathrm{Cip} 1 / \mathrm{Sdi} 1 / \mathrm{Waf} 1}$ $(9,10)$. p53 also induces Bax (11), AIP1 (12), Noxa (13), Puma (14,15), Fas (16) and PIG3 (17) which are thought to be involved in the induction of apoptosis. p53 transactivation ability can be examined by a luciferase assay using a reporter plasmid which possesses the promoter region of 13 repeats of p53-binding consensus sequence followed by luciferase cDNA (18).

In the present study, we investigated the function of a newly isolated SEREX antigen by transfection into mouse fibroblasts. It appears that the gene products reduce the 
chemosensitivity to anticancer drugs possibly by suppressing the p53 activity.

\section{Materials and methods}

Drugs. G418 and MTT (3-(4,5-dimethylthiozol-2-yl)-2,5diphenyltetrazolium bromide) were purchased from SigmaAldrich (St. Louis, MO). Vincristine (VCR), mitoxantrone, mitomycin C (MMC), methotrexate (MTX) and tunicamycin were purchased from Merck (Darmstadt, Germany). Hydroxyurea and thioguanine were obtained from Wako Pure Chemicals (Kyoto, Japan). Aclarubicin was from Yamanouchi Pharmaceutical (Tokyo, Japan), while cytosine arabinoside (AraC) was from Nippon Shinyaku (Kyoto, Japan). 5-fluorouracil (5-FU) and staurosporine were obtained from Kyowa Hakko Kogyo (Tokyo, Japan), and cis-diammine dichloroplatinum (II) (CDDP) and etoposide (VP-16) were from Nippon Kayaku (Tokyo, Japan). Methyl-nitro-ureidodeoxy-glucopyranoside (ACNU) was provided by Mitsubishi Pharma Corp. (Osaka, Japan). Ifosfamide (IFM) was obtained from Shionogi (Osaka, Japan). Trichostatin A was purchased from Cayman Chemical (Ann Arbor, MI). 5Aminoisoquinolinone (5-AIQ) and erbstatin were purchased from Alexis Biochemicals (Lausen, Switzerland). Camptothecin (CPT) and cytochalasin D were obtained from Biomol Research Laboratories (Plymouth Meeting, PA).

Cells. A human esophageal squamous cell carcinoma cell line, T.Tn $(19,20)$, was obtained from the Japan Cell Research Bank (Ibaraki, Japan). The cells were cultured in Dulbecco's modified Eagle's medium (Sigma-Aldrich), supplemented with $10 \%$ heat-inactivated fetal bovine serum. Mouse fibroblasts, NIH3T3 and activated Ha-ras-transformed NIH3T3 (clone F25) (ras-NIH) (21), were cultured in Dulbecco's modified Eagle's medium (Nissui Pharmaceutical, Tokyo, Japan) supplemented with $5 \%$ heat-inactivated bovine serum.

Sera from patients with esophageal SCC. This work was approved by the Ethics Committee of Chiba University, Graduate School of Medicine. The collection of sera was agreed upon by the patients, after obtaining their written, informed consent. The sera were obtained from a patient with esophageal SCC before treatment. The serum sample was centrifuged at $3,000 \mathrm{x}$ g for $5 \mathrm{~min}$ and the supernatant was stored at $-80^{\circ} \mathrm{C}$ until use.

SEREX screening. Total RNA was prepared from T.Tn cells by the acid guanidinium thiocyanate-phenolchloroform method (22) and purified poly(A)+RNA was obtained using the Oligotex-dT $\mathrm{d}_{30}$ (Super) mRNA Purification Kit (Takara Biochemicals, Kyoto, Japan) according to the manufacturer's instructions. Double-stranded cDNA was synthesized by conventional procedures and ligated into the EcoRI-XhoI site of $\lambda$ ZAP II phage. The original library size consisted of $1.8 \times 10^{6}$ independent clones. The immunological screening method used was performed as described previously (2-7). Monoclonalized phage cDNA clones were converted to pBluescript phagemids by in vivo excision using ExAssist helper phage (Stratagene, La Jolla, CA). Plasmid DNA was obtained from the E.coli SOLR strain transformed by phagemid.

Western blot analysis. E.coli JM109 cells that contained cDNA clones recombined in pBluescript II were cultured with or without $0.1 \mathrm{mM}$ isopropyl $\beta$-D-thiogalactoside (IPTG) for $2.5 \mathrm{~h}$. The cells were then washed with phosphatebuffered saline and lysed in SDS sample buffer followed by incubation at $100^{\circ} \mathrm{C}$ for $3 \mathrm{~min}$. The lysates were analyzed by Western blotting using 1/5000-diluted sera from patients with esophageal SCC.

Reverse transcriptase-PCR (RT-PCR). Total cellular RNA was isolated from the T.Tn esophageal SCC cell line using AquaPure RNA Isolation Kit (Bio-Rad, Hercules, CA), or from the tumor tissues using FastPure RNA Kit (Takara Bio, Otsu, Japan). Total cellular RNA was also isolated from the parent ras-NIH and its transfected cells using the AquaPure RNA Isolation kit. Reverse transcription was performed with an oligo $(\mathrm{dT})_{20}$ primer using the ThermoScript RT-PCR System (Invitrogen). The presence of AISEC transcripts was examined via PCR amplification using the following primers: sense, 5'-TGACGAGCTGAGAGAAGAAGG-3'; antisense, 5'-CCCCATCACTTTCAGGTACAC-3'. ß-actin-specific PCR primers (sense, 5'-ACCACAGCTGAGAGGGAAATC-3'; antisense, 5'-AGCACTGTGTTGGCATAGAGG-3') were used as a loading control. PCR was performed using KOD-PlusDNA polymerase (Toyobo, Osaka, Japan) as follows: an initial denaturation step at $94^{\circ} \mathrm{C}$ for $3 \mathrm{~min}$, followed by 33 cycles for AISEC or 28 cycles for $\beta$-actin of denaturation at $94^{\circ} \mathrm{C}$ for $15 \mathrm{sec}$, annealing at $60^{\circ} \mathrm{C}$ for $30 \mathrm{sec}$, and extension at $68^{\circ} \mathrm{C}$ for $30 \mathrm{sec}$, with a final extension of $5 \mathrm{~min}$ at $68^{\circ} \mathrm{C}$.

Transfection. The expression plasmid of pME18SFL3-AISEC was obtained as previously described (23). The plasmid and neo gene construct were co-transfected into ras-NIH cells using Lipofectamine Plus Reagent (Invitrogen, Carlsbad, CA) according to the manufacturer's instructions. The transfected cells were selected by a culture in the presence of G418 $(400 \mu \mathrm{g} / \mathrm{ml})$ for 2 weeks as described $(24,25)$. We stably obtained AISEC-transfected clones, designated as FAISEC-1 to -6 .

MTT method for assessing viability. The inhibitory effects of the drugs on the proliferation of cultured cells were examined by the MTT method of Mosmann (26) as described previously (27). Five thousand cells were plated in each well and cultured for 3 days. Cell viability was quantified by measuring the absorbance at $570 \mathrm{~nm}$ after incubation with MTT for $4 \mathrm{~h}$. The results are shown as percentages of the control results.

Luciferase assay. Luciferase reporter plasmid (PG13-luc) containing 13 repeats of p53-binding sites of p21 and its mutated control plasmid (PG15-luc) were provided by Dr Bert Vogelstein (Howard Hughes Medical Institute) (18). ras-NIH cells were co-transfected with $5 \mathrm{ng}$ of PG13-luc, 10 ng of Renilla luciferase internal control plasmid, pRLCMV (Promega, Madison, WI) (28), 0 or $0.2 \mu \mathrm{g}$ of wild-type p53 expression plasmid (29) and 0-1 $\mu \mathrm{g}$ of pME18-FL3AISEC. Empty vector pME18-FL3 was also co-transfected 


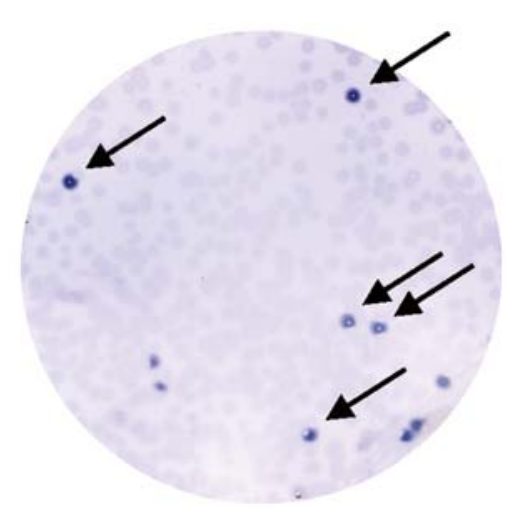

Figure 1. Results of SEREX screening. Phage clones of AISEC isolated by first screening were infected into $E$. coli. Bacterial extract containing cDNA products were blotted onto the membranes and probed with antibodies in the serum of the patients with esophageal SCC. The arrows indicate positive reactions.

to maintain constant amounts of DNA. Luciferase activity was measured $48 \mathrm{~h}$ after the transfection by the DualLuciferase Reporter Assay System (Promega) according to the manufacturer's instructions as previously described $(25,30)$.

\section{Results}

Isolation of AISEC cDNA by SEREX. The phage expression library was constructed using mRNA derived from the human esophageal SCC cell line, T.Tn (2,3). A total of $1 \times 10^{6}$ cDNA clones were screened using the sera from an esophageal cancer patient, and a reactive clone was isolated. The results of the second screening is shown in Fig. 1. A DNA sequence analysis and a search for homologous sequence in NCBIaccessible databases revealed that the isolated clone was similar but not identical (97\% homology) to Homo sapiens cDNA clone IMAGE:4548538 (Accession No. BG333226). This gene was designated as AISEC (antigen identified by SEREX for esophageal carcinoma). AISEC is composed of 1,910 bases which encodes an open reading frame of 338 amino acids. The nucleotide sequence of AISEC cDNA and amino acid sequence of putative AISEC gene product are shown in Fig. 2. AISEC is an intronless gene and localized at chromosome 5q31.2. Sequence analysis by the SMART service (http://smart.embl-heidelberg.de/) revealed that amino acids between 22 and 113 of AISEC protein demonstrate homology with K-box, which is a possible coiled coil structure and they may also play a role in multimer formation, however, no further information is available at present.

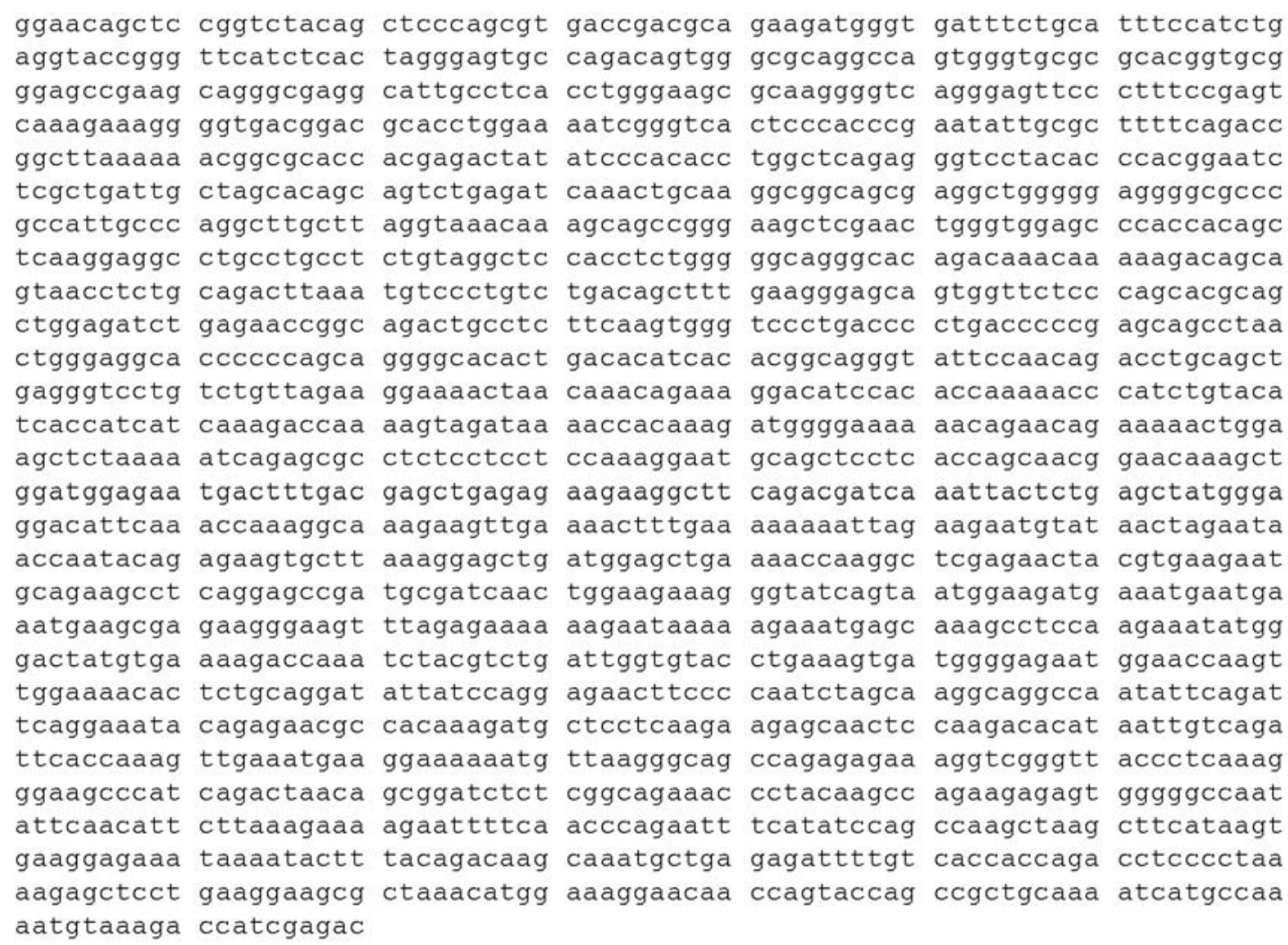

MGKKQNRKTG SSKNQSASPP PKECSSSPAT EQSWMENDFD ELREEGFRRS NYSELWEDIQ TKGKEVENFE KKLEECITRI TNTEKCLKEL MELKTKAREL REECRSLRSR CDQLEERVSV MEDEMNEMKR EGKFREKRIK RNEQSLQEIW DYVKRPNLRL IGVPESDGEN GTKLENTLQD IIQENFPNLA RQANIQIQEI QRTPQRCSSR RATPRHIIVR FTKVEMKEKM LRAAREKGRV TLKGKPIRLT ADLSAETLQA RREWGPIFNI LKEKNFQPRI SYPAKLSFIS EGEIKYFTDK QMLRDFVTTR PPLKELLKEA LNMERNNQYQ PLQNHAKM

Figure 2. Nucleotide and amino acid sequences of AISEC. Nucleotide sequence of AISEC cDNA (A) and amino acid sequence of putative AISEC gene product $(\mathrm{B})$ are shown. 


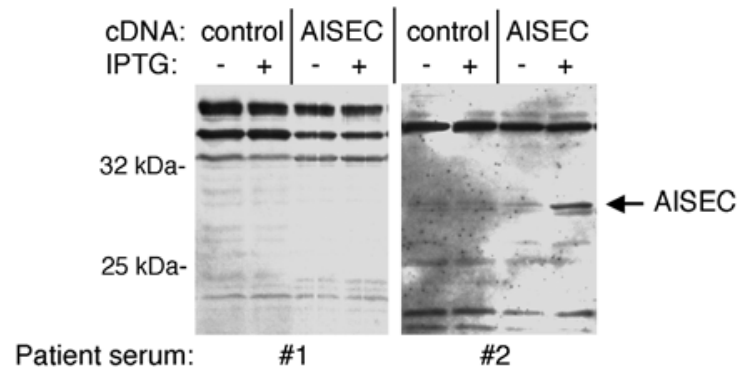

Figure 3. Recognition of AISEC by serum antibodies in patients with esophageal SCC. E. coli containing AISEC cDNA expression vector was treated with IPTG for $2.5 \mathrm{~h}$, and cell lysates were subsequently subjected to a Western blot analysis using the sera from esophageal SCC patients \#1 and \#2. An arrow indicates the IPTG-induced polypeptide that represents the encoded cDNA product.

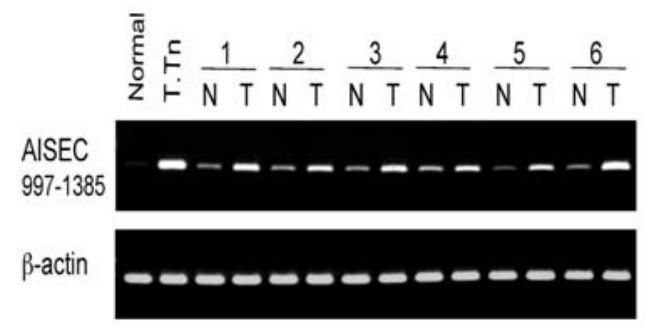

Figure 4. Expression of AISEC mRNA in normal and esophageal SCC tissues. The expressions of AISEC (upper panel) and B-actin (lower panel) mRNA were examined by RT-PCR in specimens of normal (N) and carcinoma (T) tissues resected from patients 1 to 6 (P1-P6). 'Normal' and 'T.Tn' represent the products from RNA of normal esophageal keratinocytes obtained from Cybrdi and the T.Tn esophageal SCC cell line, respectively.

Presence of AISEC antibodies in sera of patients with esophageal SCC. E. coli JM109 cells that contained AISEC cDNA recombined in pBluescript II were cultured with IPTG to induce AISEC expression. The cell lysates were analyzed by Western blotting using sera from patients with esophageal SCC. Representative results are shown in Fig. 3. An IPTGdependent reaction was observed by using patient serum \#2 but not \#1. The molecular weight was approximately $40 \mathrm{kDa}$, which equaled the estimated size from the sequence analysis. As a result, the patient serum \#1 and \#2 were thus considered to be negative and positive, respectively, for anti-AISEC antibodies.

Expression of AISEC in esophageal SCC. The expression levels of AISEC mRNA in esophageal tissue specimens that contained esophageal carcinoma and normal cells, were examined by RT-PCR analysis. For negative and positive controls, normal esophageal keratinocytes and the T.Tn esophageal SCC cell line, respectively, were used. The expression of AISEC was almost undetectable in normal esophageal keratinocytes whereas it was clearly observed in T.Tn cells (Fig. 4). The expression levels of AISEC mRNA in carcinoma tissues were higher than those in the normal tissues of the same patients, suggesting that AISEC may have a role in tumor cells.

Transfection of AISEC cDNA into ras-NIH cells. The biological function of AISEC in transformed cells was

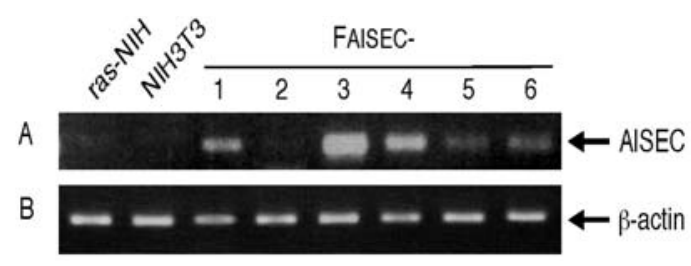

Figure 5. Expression of AISEC mRNA in AISEC transfectants. The expression of mRNA of AISEC (A) and B-actin (B) was examined by RT-PCR. The cells used were ras-NIH, NIH3T3, and FAISEC-1 to 6. Each specific PCR product is indicated by arrows. ras- $\mathrm{NIH}$

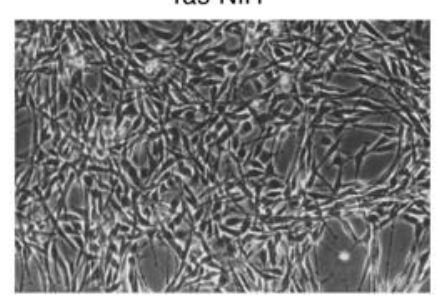

FAISEC-3

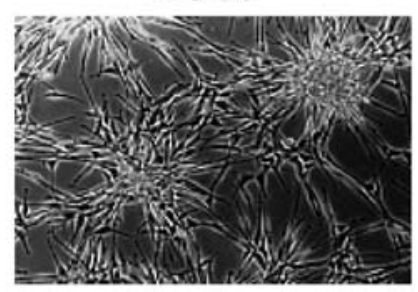

Figure 6. The phase micrographs of parental ras-NIH and FAISEC-3 cells.

examined by an enforced expression of AISEC in ras-NIH cells. AISEC cDNA constructed in pME18S-FL3 expression vector (23) and neo gene were stably co-transfected into rasNIH cells. After selection with G418, the isolated clones were designated FAISEC-1 to -6 . The expression of AISEC mRNA in each clone was examined by RT-PCR as described (25). Among the 6 clones, FAISEC- 3 showed the highest expression of AISEC mRNA (Fig. 5). No apparent expression was observed in parental ras-NIH and NIH3T3 cells. The phase morphology of FAISEC-3 cells is shown in Fig. 6. In comparison to the parental cells, longer processes and more frequent cell aggregation were observed in the FAISEC-3 cells, thus suggesting that the malignancy was exacerbated by transfection with AISEC.

Comparison of chemosensitivity against anticancer drugs between ras-NIH and FAISEC-3 cells. ras-NIH and FAISEC-3 cells were cultured for 3 days in the presence of various concentrations of cytotoxic drugs. The relative viability was evaluated by an MTT colorimetric assay (Fig. 7). FAISEC-3 cells were more sensitive to erbstatin, staurosporine, trichostatin A and tunicamycin but more resistant to such anticancer drugs as MMC, IFM, VCR, CPT, VP-16, cytochalasin D and ACNU than the parental ras-NIH cells. FAISEC-3 cells were also more resistant to 5-AIQ, which is an inhibitor of poly(ADP-ribose) poly-merase-1 (PARP) (31). On the other hand, no obvious difference in sensitivity was detected between those cells for other anticancer drugs such as AraC, CDDP, 5-FU, MTX, aclarubicin, hydroxyurea, mitoxantrone and thioguanine (data not shown).

Suppression of p53 transactivation activity by AISEC. The transcriptional activity of p53 was then examined by a luciferase assay. p53 reporter plasmid, PG13-luc, and Renilla luciferase internal control plasmid were co-transfected with 
ㅁ ras-NIH

$\triangle$ FAISEC-3

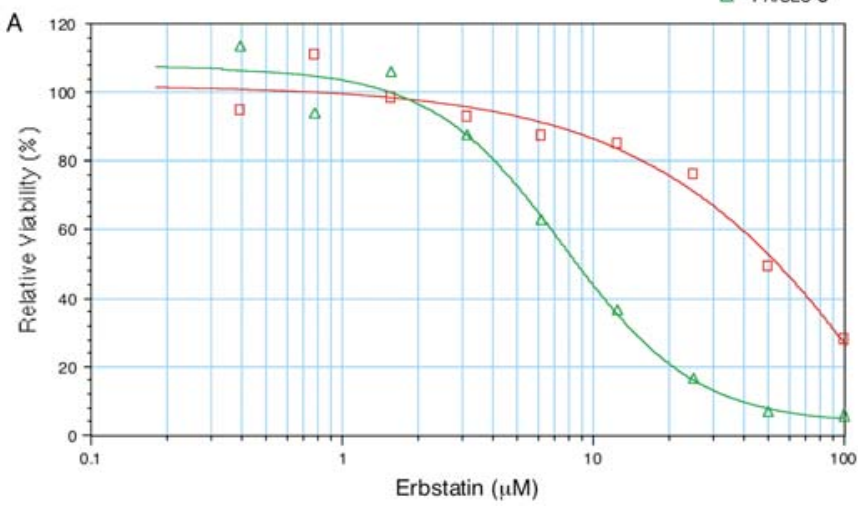

口 ras-NIH

$\triangle$ FAISEC-3

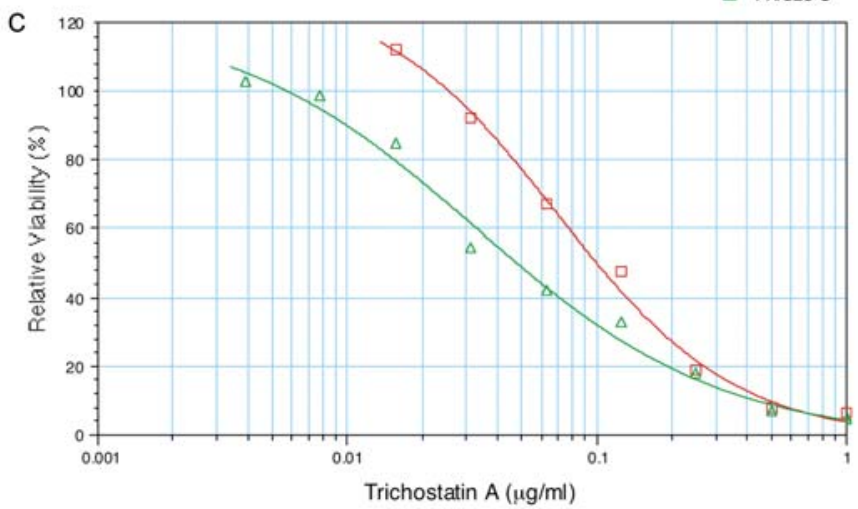

口 ras- $\mathrm{NIH}$

$\triangle$ FAISEC-3

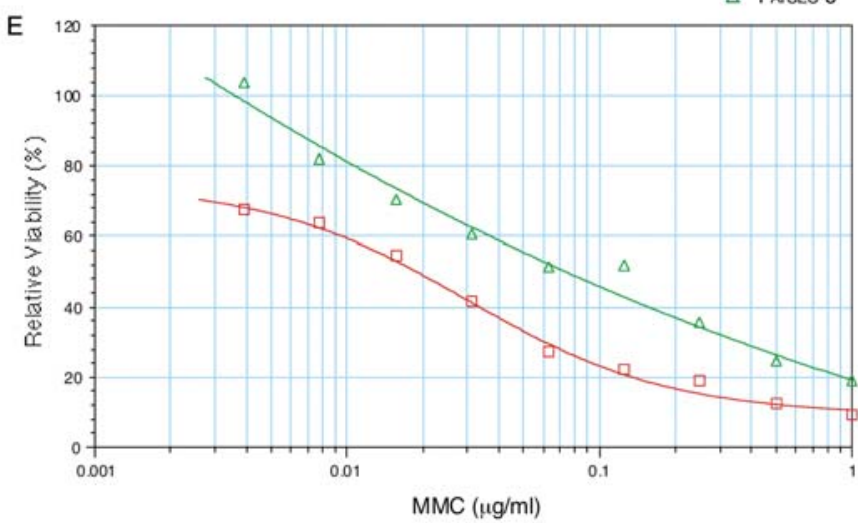

ㅁ ras-NIH

$\triangle$ FAISEC-3

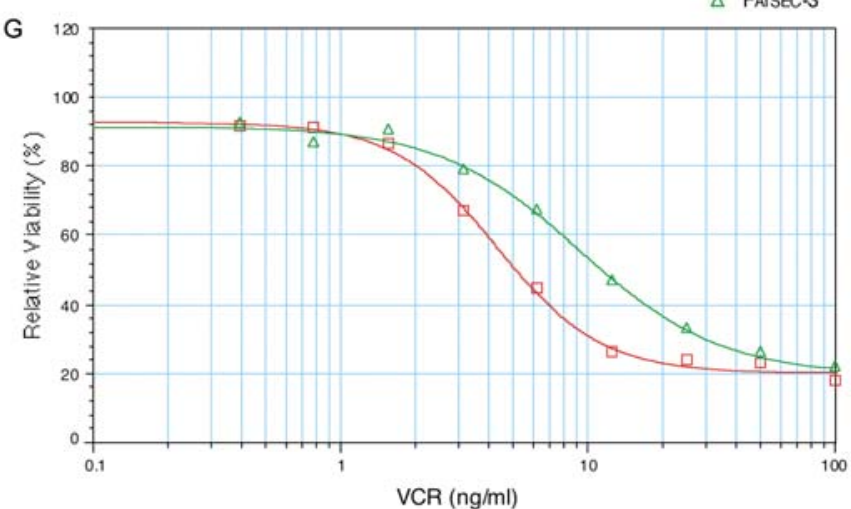

口 ras-NIH

$\triangle$ FAISEC-3

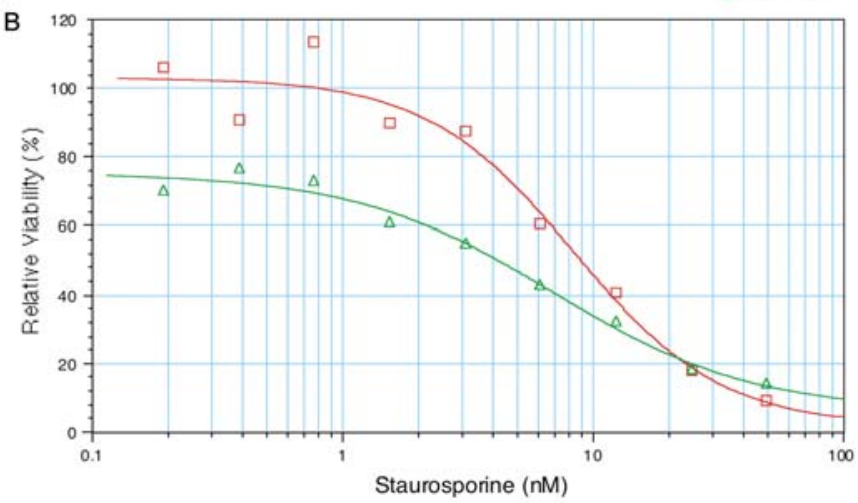

ㅁ ras-NIH

$\triangle$ FAISEC-3

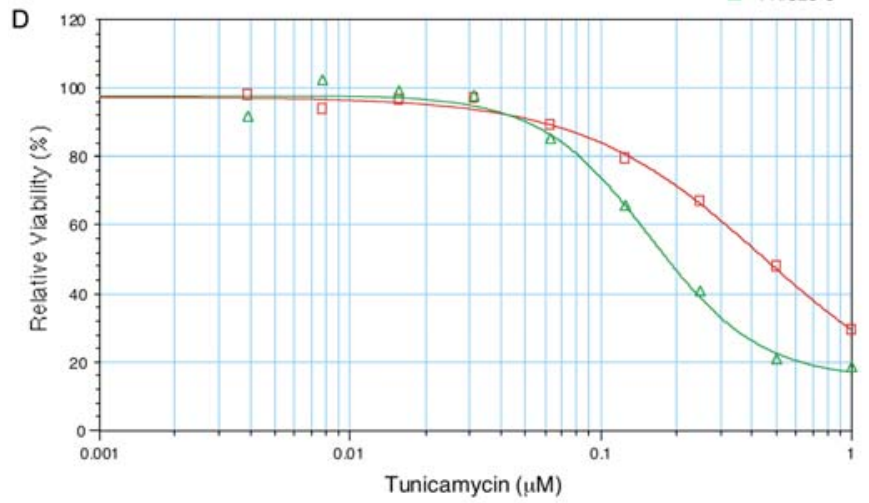

ㅁ ras- $\mathrm{NIH}$

$\triangle$ FASEC-3

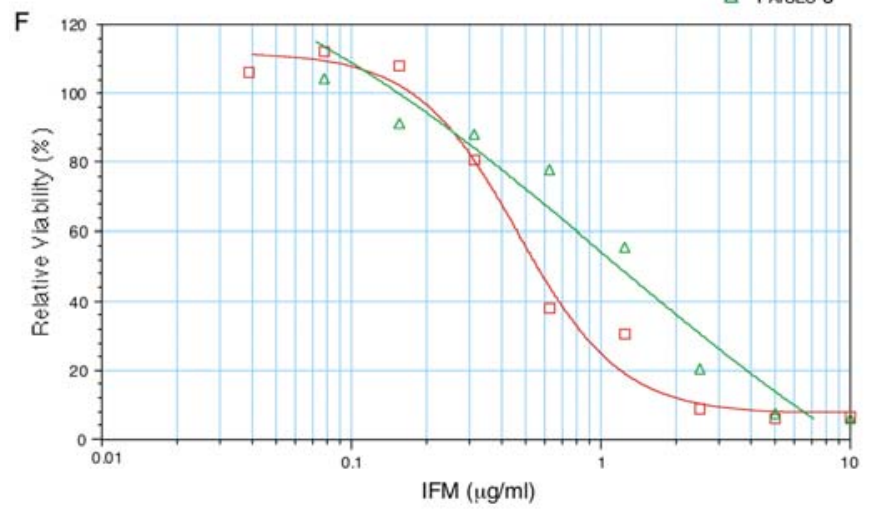

ㅁ ras- $\mathrm{NIH}$

$\triangle$ FAISEC-3

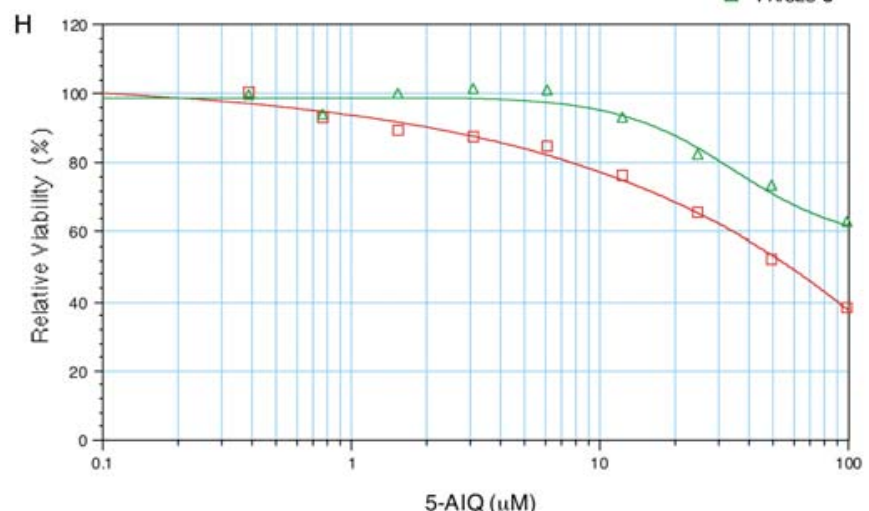

Figure 7. The effect of AISEC on the chemosensitivity of parental and transfected cells toward cytotoxic drugs. Parental ras-NIH ( $\square$ ) and FAISEC-3 ( $\Delta$ ) cells were cultured in the presence of erbstatin (A), staurosporine (B), trichostatin A (C), tunicamycin (D), MMC (E), IFM (F), VCR (G) and 5-AIQ (H). 

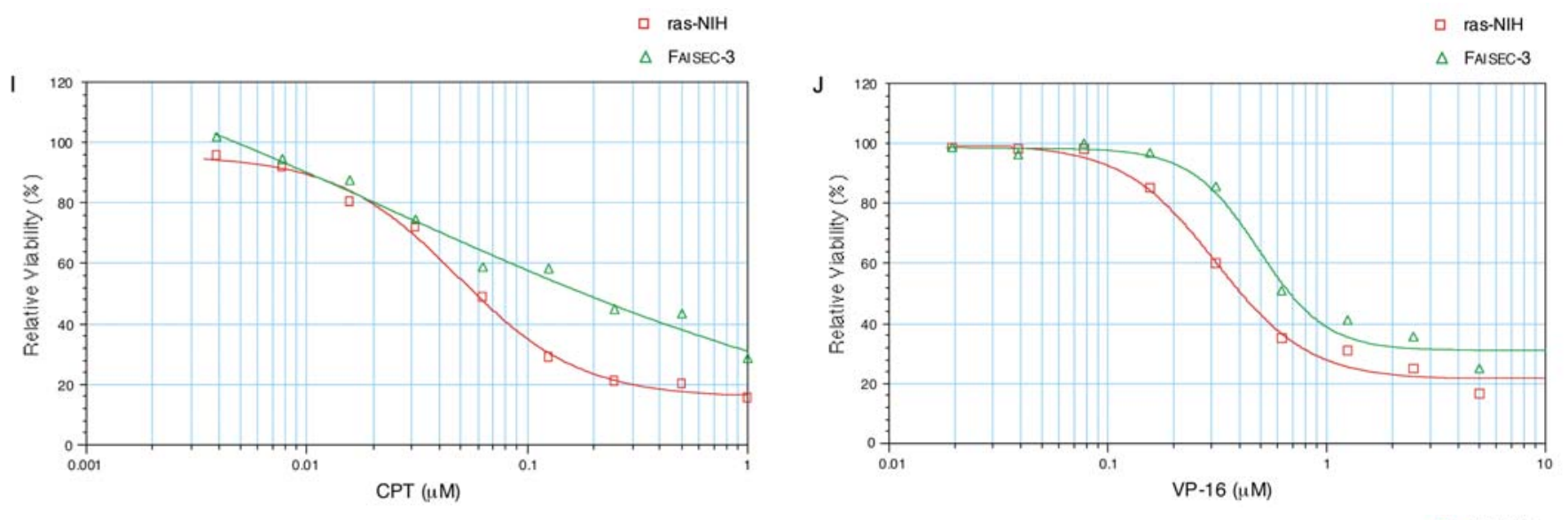

口 ras-NIH

$\triangle$ FAISEC-3

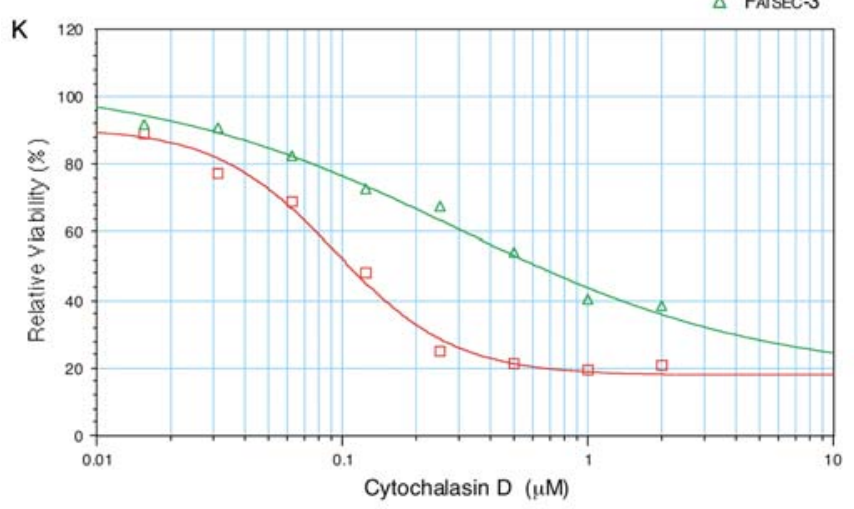

ㅁ ras-NIH

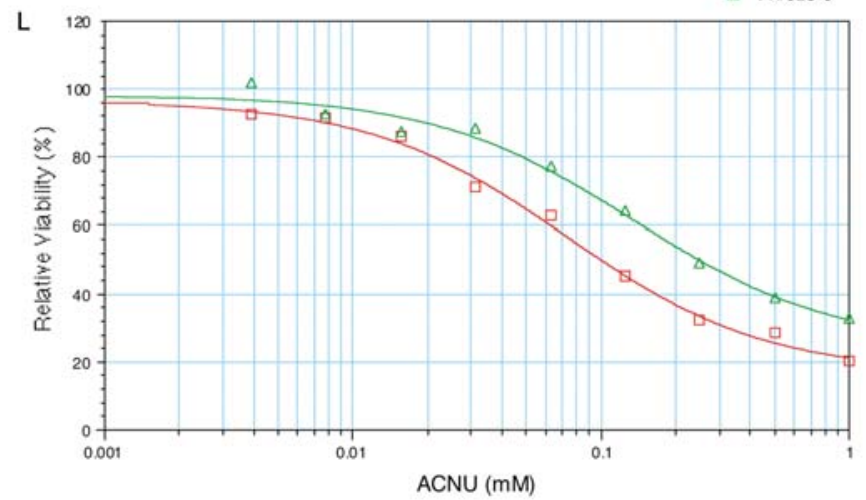

Figure 7 (continued). The effect of AISEC on the chemosensitivity of parental and transfected cells toward cytotoxic drugs. Parental ras-NIH (a) and FAISEC-3 $(\Delta)$ cells were cultured in the presence of CPT (I), VP-16 (J), cytochalasin D (K) and ACNU (L) for 3 days. The viabilities were measured by an MTT assay. The abscissa and ordinate represent the concentration of the test drugs and the relative viability vs. that in the absence of test drugs, respectively.

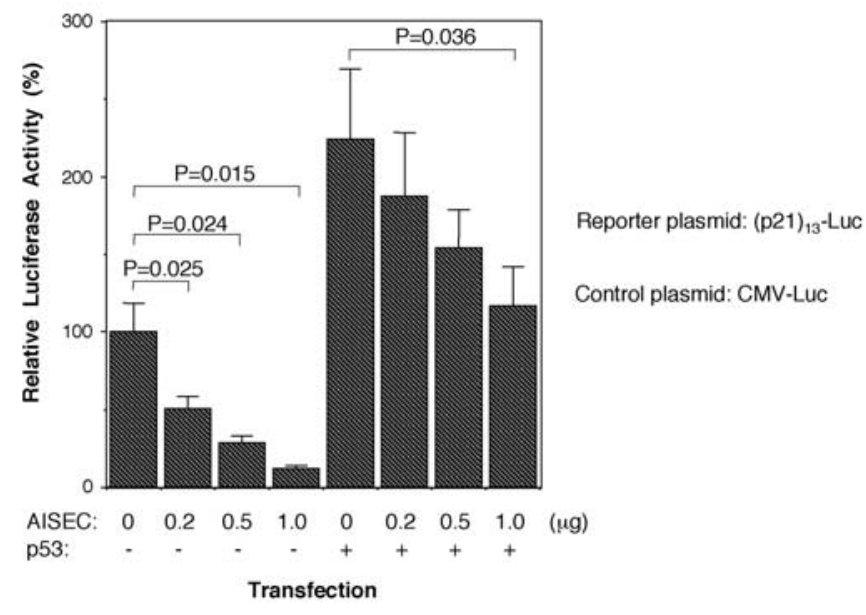

Figure 8 . The transactivation activity of p53. ras-NIH cells were co-transfected with $5 \mathrm{ng}$ of PG13-luc, $10 \mathrm{ng}$ of Renilla luciferase internal control plasmid, $0(-)$ or $0.2 \mu \mathrm{g}(+)$ of wild-type 553 expression plasmid and $0,0.2$, 0.5 or $1.0 \mu \mathrm{g}$ of pME18SFL3-AISEC. The empty vector pME18SFL3 was also co-transfected to maintain the total amounts of DNA constant. The luciferase activity was measured $48 \mathrm{~h}$ after the transfection. Each column and bar represent the mean and standard deviation, respectively, of three independent experiments. The P-values obtained by Student's t-test are also shown.

AISEC expression plasmid into ras-NIH cells. The relative luciferase activity decreased after transfection with AISEC

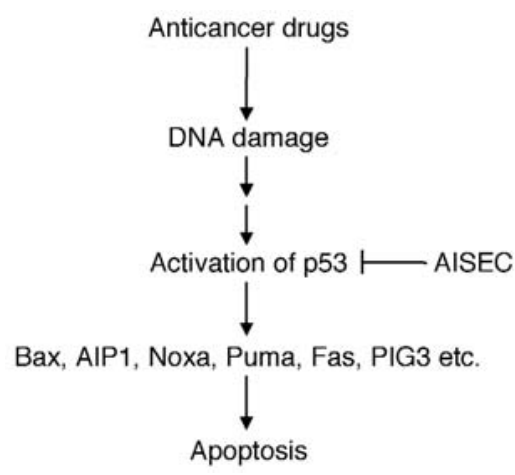

Figure 9. Possible action mechanism of AISEC. DNA damage induced by the treatment with anticancer drugs activates p53, which thus induces apoptosis via its target genes such as Bax, AIP1, Noxa, Puma, Fas and PIG3. AISEC reduced chemosensitivity against anticancer drugs possibly by suppressing the transactivation activity of $\mathrm{p} 53$.

cDNA in a dose-dependent manner, and a significant decrease was observed at co-transfection with $0.2 \mu \mathrm{g}$ of AISEC plasmid DNA (Fig. 8). After transfection with $1 \mu \mathrm{g}$ of AISEC cDNA, the luciferase activity decreased to as low as $15 \%$ of the control. This suppressive activity of AISEC against p53 was also observed when wild-type p53 cDNA was co-transfected. Wild-type p53 stimulated the p 21 promoter $>2$-fold as expected. This stimulatory activity of p53 was almost 
completely suppressed by co-transfection with $1 \mu \mathrm{g}$ of AISEC plasmid DNA (Fig. 8). In comparison to PG13-luc, the mutated reporter plasmid, PG15-luc, showed a much weaker luciferase activity (data not shown). This suggests that AISEC exhibited a p53-suppressive activity not at a distant upstream signaling pathway, but instead at a location in the vicinity of the p53 protein itself.

\section{Discussion}

SEREX screening is effective for identifying new tumor markers. We previously carried out a large scale screening of SEREX for esophageal SCC (2-8). It was thus found that SEREX antigens may induce their serum antibodies possibly by the overexpression of wild-types, the expression of alternative splicing variants and/or altered protein processing. As a result, SEREX antigens are not only possible tumor markers but also potential participants in tumor development. In fact, most of the esophageal SEREX antigens we identified were related to cancer (6). Therefore, we examined the biological activities of AISEC by transfection of its cDNA into mouse fibroblasts.

Six stably transfected clones were isolated, of which FAISEC-3 showed the highest expression of AISEC mRNA (Fig. 5). FAISEC-3 cells showed a round and refractile morphology with long processes (Fig. 6), which was typical for such malignantly transformed NIH3T3 cells (32). Although the growth rate and the anchorage-independent growth had not apparently changed (data not shown), AISEC-expressing cells were more resistant to anticancer drugs such as MMC, IFM, VCR, CPT, VP-16, cytochalasin D and ACNU than the parental cells (Fig. 7). It should be noted that some anticancer drugs such as MMC, IFM, CPT and VP-16 are genotoxic (33), and therefore, can induce p53-mediated apoptosis. 5-AIQ can also cause genotoxic effects by inhibiting PARP (31) which plays a part in DNA repair activity (34). Therefore, the suppression of p53 transactivity by AISEC may account for the decrease in chemosensitivity of FAISEC- 3 cells against anticancer drugs and 5-AIQ. A schematic drawing of the possible action mechanism of AISEC is shown in Fig. 9.

On the other hand, AISEC increased the chemosensitivity against erbstatin and staurosporine (Fig. 7). Erbstatin and staurosporine are not only potent protein kinase inhibitors but also apoptosis inducers (35-37). It was reported that p53 is activated due to the phosphorylation by ATM and ATR after genotoxic stresses $(38,39)$. Although it is not known whether erbstatin and starurosporine affect the phosphorylation of p53, AISEC could be involved in such phosphorylation signaling pathways. Trichostatin A is a histone deacetylase inhibitor, which can elevate the general transcriptional activity by increasing the levels of acetylation of histone (40). Tunicamycin is an inhibitor of glycosylation (41). Sensitivity against trichostatin A and tunicamycin increased in AISECexpressing cells (Fig. 7), thus suggesting that acetylation and glycosylation are also involved in the AISEC signaling pathway.

The present study raised the possibility that AISEC activity can be applied to cancer therapy. For example, the chemical inhibitors of AISEC may increase the p53 activity, thus resulting in the induction of growth arrest or the apoptosis of tumor cells. The development of AISEC inhibitors is therefore expected to have a positive effect in the development of future cancer chemotherapy.

In conclusion, the present study suggests that an esophageal SCC SEREX antigen, AISEC, can reduce chemosensitivity against anticancer drugs via p53.

\section{Acknowledgements}

We are grateful to Dr Bert Vogelstein (Howard Hughes Medical Institute) for providing p53 expression plasmid and p53 reporter plasmids. We also thank Ms. Masae Suzuki and Akiko Kimura for their helpful technical assistance. This work was partly supported by a Grant for 21 st Century COE (Center of Excellence) Program and a Grant-in-Aid for Scientific Research from the Ministry of Education, Culture, Sports, Science and Technology of Japan.

\section{References}

1. Isono $\mathrm{K}$ and Ochiai $\mathrm{T}$ : Recent advances of treatment of cancer of the esophagus (review). Ann Cancer Res Ther 1: 9-16, 1992.

2. Nakashima K, Shimada H, Ochiai T, et al: Serological identification of TROP2 by recombinant cDNA expression cloning using sera of patients with esophageal squamous cell carcinoma. Int J Cancer 112: 1029-1035, 2004.

3. Shimada H, Nakashima K, Ochiai T, et al: Serological identification of tumor antigens of esophageal squamous cell carcinoma. Int J Oncol 26: 77-86, 2005.

4. Kuboshima M, Shimada H, Liu TL, et al: Identification of a novel SEREX antigen, SLC2A1/GLUT1, in esophageal squamous cell carcinoma. Int J Oncol 28: 463-468, 2006.

5. Kuboshima M, Shimada H, Liu TL, et al: Presence of serum tripartite motif-containing 21 antibodies in patients with esophageal squamous cell carcinoma. Cancer Sci 97: 380-386, 2006.

6. Hiwasa T, Shimada H, Ochiai T and Takiguchi M: Serological identification of antigens by recombinant cDNA expression cloning (SEREX) using antibodies from patients with esophageal squamous cell carcinoma. In: Moleculomics and Thereafter. Hiwasa T (ed.) Research Signpost, Kerala, pp99-117, 2006.

7. Shimada H, Kuboshima M, Shiratori T, et al: Serum antimyomegalin antibodies in patients with esophageal squamous cell carcinoma. Int J Oncol 30: 97-103, 2007.

8. Shiratori T, Shimada H, Kagaya A, et al: Sensitization against anticancer drugs by transfection with UBE2I variant gene into ras-NIH3T3 mouse fibroblasts. Anticancer Res 27: 3227-3234, 2007.

9. Bunz F, Dutriaux A, Lengauer C, et al: Requirement for p53 and p21 to sustain $G_{2}$ arrest after DNA damage. Science 282: 1497-1501, 1998.

10. El-Deiry WS, Tokino T, Velculescu VE, et al: WAF1, a potential mediator of p53 tumor suppression. Cell 75: 817-825, 1993.

11. Miyashita T and Reed JC: Tumor suppressor p53 is a direct transcriptional activator of the human bax gene. Cell 80: 293-299, 1995.

12. Oda K, Arakawa H, Tanaka T, et al: p53AIP1, a potential mediator of p53-dependent apoptosis, and its regulation by Ser-46-phosphorylated p53. Cell 102: 849-862, 2000.

13. Oda E, Ohki R, Murasawa H, et al: Noxa, a BH3-only member of the Bcl-2 family and candidate mediator of p53-induced apoptosis. Science 288: 1053-1058, 2000.

14. Yu J, Zhang L, Hwang PM, Kinzler KW and Vogelstein B: PUMA induces the rapid apoptosis of colorectal cancer cells. Mol Cell 7: 673-682, 2001.

15. Nakano K and Vousden KH: PUMA, a novel proapoptotic gene, is induced by p53. Mol Cell 7: 683-694, 2001.

16. Owen-Schaub LB, Zhang W, Cusack JC, et al: Wild-type human p53 and a temperature-sensitive mutant induce Fas/ APO-1 expression. Mol Cell Biol 15: 3032-3040, 1995.

17. Polyak K, Xia Y, Zweier JL, Kinzler KW and Vogelstein B: A model for p53-induced apoptosis. Nature 389: 300-305, 1997.

18. El-Deiry WS, Kern SE, Pietenpol JA, Kinzler KW and Vogelstein B: Definition of a consensus binding site for p53. Nat Genet 1: 45-49, 1992. 
19. Takahashi K, Kanazawa H, Chan H, Hosono T, Takahara M and Sato K: A case of esophageal carcinoma metastatic to the mandible and characterization of two cell lines (T.T. and T.Tn.). Jpn J Oral Maxillofac Surg 36: 307-316, 1990.

20. Shimada H, Shimizu T, Ochiai T, et al: Preclinical study of adenoviral p53 gene therapy for esophageal cancer. Surg Today 31: 597-604, 2001

21. Sekiya T, Fushimi M, Mori H, Hirohashi S, Nishimura S and Sugimura T: Molecular cloning and the total nucleotide sequence of the human c-Ha-ras-1 gene activated in melanoma from a Japanese patient. Proc Natl Acad Sci USA 81: 4771-4775, 1998

22. Chomczynski P and Sacchi N: Single-step method of RNA isolation by acid guanidinium thiocyanate-phenol-chloroform extraction. Anal Biochem 162: 156-159, 1987.

23. Suzuki Y, Yoshitomo K, Maruyama K, Suyama A and Sugano S Construction and characterization of a full length-enriched and a 5'-end-enriched cDNA library. Gene 200: 149-156, 1997.

24. Hiwasa T, Sawada T and Sakiyama S: Synergistic induction of anchorage-independent growth of NIH3T3 fibroblasts by cysteine proteinase inhibitors and a tumor promoter. J Biol Chem 271: 9181-9184, 1996.

25. Liu TL, Shimada H, Ochiai T, et al: Enhancement of chemosensitivity toward peplomycin by calpastatin-stabilized NF-кB p65 in esophageal carcinoma cells: possible involvement of Fas/ Fas-L synergism. Apoptosis 11: 1025-1037, 2006.

26. Mosmann T: Rapid colorimetric assay for cellular growth and survival: application to proliferation and cytotoxicity assays Immunol Methods 65: 55-63, 1983.

27. Hiwasa T, Shimada H, Sakaida T, et al: Drug-sensitivity pattern analysis of study of functional relationship between gene products. FEBS Lett 552: 177-183, 2003.

28. Kitagawa M, Oyama T, Kawashima T, et al: A human protein with sequence similarity to Drosophila mastermind coordinates the nuclear form of notch and a CSL protein to build a transcriptional activator complex on target promoters. Mol Cell Biol 21: 4337-4346, 2001.

29. Baker SJ, Markowitz S, Fearon ER, Willson JK and Vogelstein B: Suppression of human colorectal carcinoma cell growth by wild-type p53. Science 249: 912-915, 1990.

30. Fujita T, Nolan GP, Liou HC, Scott ML and Baltimore D: The candidate proto-oncogene bcl-3 encodes a transcriptional coactivator that activates through NF-кB p50 homodimers. Genes Dev 7: 1354-1363, 1993.
31. Wayman N, McDonald MC, Thompson AS, Threadgill MD and Thiemermann C: 5-Aminoisoquinolinone, a water-soluble potent inhibitor of poly(adenosine 5'-diphosphate ribose) polymerase, reduces myocardial infarct size. Eur J Pharmacol 430: 93-100, 2001

32. Hiwasa T and Nakagawara A: Suppression of transformed phenotypes of Ha-ras-transformed NIH3T3 cells by caspase-2. Biochem Biophys Res Commun 250: 741-746, 1998.

33. Brown JM and Wouters BG: Apoptosis, p53, and tumor cell sensitivity to anticancer agents. Cancer Res 59: 1391-1399, 1999.

34. De Murcia JM, Niedergang C, Trucco C, et al: Requirement of poly(ADP-ribose) polymerase in recovery from DNA damage in mice and in cells. Proc Natl Acad Sci USA 94: 7303-7307, 1997.

35. Umezawa H, Imoto M, Sawa T, et al: Studies on a new epidermal growth factor-receptor kinase inhibitor, erbstatin, produced by MH435-hF3. J Antibiot (Tokyo) 39: 170-173, 1986.

36. Tamaoki T, Nomoto H, Takahashi I, Kato Y, Morimoto M and Tomita F: Staurosporine, a potent inhibitor of phospholipid/ $\mathrm{Ca}^{++}$-dependent protein kinase. Biochem Biophys Res Commun 135: 397-402, 1986

37. Hiwasa T, Arase Y, Chen Z, et al: Stimulation of ultravioletinduced apoptosis of human fibroblast $\mathrm{UV}^{\mathrm{r}}-1$ cells by tyrosine kinase inhibitors. FEBS Lett 444: 173-176, 1999.

38. Canman CE, Lim DS, Cimprich KA, et al: Activation of the ATM kinase by ionizing radiation and phosphorylation of p53. Science 281: 1677-1679, 1998 .

39. Tibbetts RS, Brumbaugh KM, Williams JM, et al: A role for ATR in the DNA damage-induced phosphorylation of p53. Genes Dev 13: 152-157, 1999.

40. Yoshida M, Kijima M, Akita M and Beppu T: Potent and specific inhibition of mammalian histone deacetylase both in vivo and in vitro by trichostatin A. J Biol Chem 265: 17174-17179, 1990.

41. Leavitt R, Schlesinger S and Kornfeld S: Tunicamycin inhibits glycosylation and multiplication of Sindbis and vesicular stomatitis viruses. J Virol 21: 375-385, 1977. 